Al-Mashlahah: Jurnal Hukum dan Pranata Sosial Islam, VOL : 07, NO : 1, Agustus 2019

DOI : 10.30868/am.v7i1.544

ISSN : 2339-2800 (Media Cetak)

ISSN : 2581-2556 (Media Online)

\title{
ANALISIS MAQASHID SYARIAH PADA PENAMBANGAN PASIR BESI PANTAI CIPATUJAH TASIKMALAYA
}

\author{
Trisna Wijaya Joni ${ }^{1}$ \\ ${ }^{1}$ Fakultas Agama Islam Universitas Siliwangi Tasikmlaya \\ email:trisnafaiz@gmail.com
}

\begin{abstract}
Falah or happiness is the goal of every human being. One indicator of achieving falah is the fulfillment of clothing, food and shelter needs. In an effort to achieve this goal, humans use nature that Allah has created to fulfill their needs. But Allah Almighty has determined the boundaries in his Shari'a which are related to human efforts in exploring and exploiting natural resources, so that these efforts do not have a negative impact on the environment or others. One of the activities of exploitation of natural resources is iron sand mining located in the Cipatujah area of Tasikmalaya Regency. The existence of these mining activities has positive and negative impacts. This study aims to examine the positive and negative impacts caused by iron sand mining on the coast of Cipatujah, with maqashid sharia as its analytical tool.
\end{abstract}

Keywords: maqashid sharia, iron sand, cipatujah, mining.

\begin{abstract}
ABSTRAK
Falah atau kebahagiaan adalah tujuan dari setiap manusia. Salah satu indikator tercapainya falah adalah terpenuhinya kebutuhan sandang, pangan, dan papan. Dalam upaya mencapai tujuannya tersebut, manusia memanfaatkan alam yang memang sudah diciptakan Allah S.W.T. untuk memenuhi kebutuhannya. Akan tetapi Allah S.W.T. telah menentukan batasan-batasan dalam syariat yang berhubungan dengan upaya manusia dalam mengekplorasi dan mengeksploitasi kekayaan alam, agar upayanya tersebut tidak menimbulkan dampak negatif baik bagi lingkungan maupun pihak yang lain. Salah satu kegiatan eksploitasi sumber daya alam adalah penambangan pasir besi yang berlokasi di wilayah Cipatujah Kabupaten Tasikmalaya. Keberadaan kegiatan penambangan tersebut memiliki dampak positif dan negatif. Penelitian ini bertujuan untuk mengkaji apa dampak positif dan negatif yang ditimbulkan oleh kegiatan penambangan pasir besi di pantai Cipatujah, dengan maqashid syariah sebagai alat analisisnya.
\end{abstract}

Kata kunci: maqashid syariah, pasir besi, cipatujah, penambangan. 


\section{A. PENDAHULUAN}

Falah atau kebahagiaan adalah tujuan dari setiap manusia. Falah dapat terwujud jika terpenuhi kebutuhankebutuhan hidup manusia secara seimbang. Tercukupinya kebutuhan masyarakat akan memberikan dampak yang disebut dengan maslahah. ${ }^{1}$ Dalam upaya mencapai tujuannya tersebut, manusia memanfaatkan alam yang memang sudah diciptakan Allah S.W.T. untuk memenuhi kebutuhan manusia.

Allah S.W.T. menciptakan bumi dan seisinya untuk dimanfaatkan oleh manusia dalam upayanya untuk memenuhi berbagai kebutuhannya selama hidup di dunia yang meliputi kebutuhan sandang, pangan, dan papan. Alam semesta sebagai ciptaan-Nya, Allah S.W.T. menjamin berbagai kebutuhan dan keperluan manusia yang senantiasa bertambah pada setiap peringkat kehidupan ini. Sebagaimana firman Allah dalam Surat Hud Ayat 6 berikut ini:

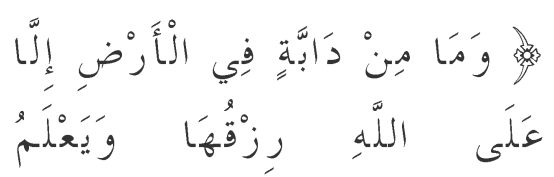

1 Pusat Pengkajian dan Pengembangan Ekonomi Islam. (2008). Ekonomi Islam. Jakarta: PT RajaGrafindo Persada. hlm. 2.

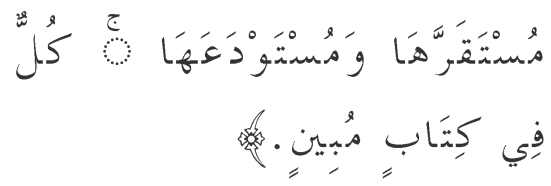

"Dan tidak ada suatu binatang melata pun di bumi melainkan Allah-lah yang memberi rezekinya, dan Dia mengetahui tempat berdiam binatang itu dan tempat penyimpanannya. Semuanya tertulis dalam Kitab yang nyata (Lauh Mahfuzh)."

Islam mengakui bahwa salah satu faktor produksi yang paling penting adalah tanah yang di atasnya kita dapat berjalan, mendirikan rumah serta melakukan apa saja sesuai yang kita inginkan. Allah S.W.T. berfirman dalam Surat Al-Baqarah Ayat 36 yang berbunyi:

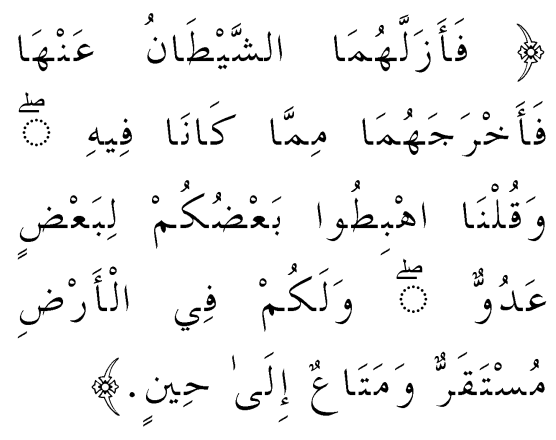

"Lalu keduanya digelincirkan oleh setan dari surga itu dan dikeluarkan dari keadaan semula dan Kami berfirman: "Turunlah kamu! sebagian kamu menjadi musuh bagi yang lain, dan bagi kamu ada tempat kediaman di bumi, dan kesenangan hidup sampai waktu yang ditentukan." 
Terdapat banyak hadits yang menunjukkan bahwa Rasulullah S.A.W. memerintahkan umat Islam supaya bekerja bersungguh-sungguh untuk mendapatkan penghidupan mereka dari tanah, di antaranya adalah hadits berikut ini:

"Carilah penghidupan kamu dari khazanah (kekayaan) bumi yang tersembunyi" (H.R. Ath-Thabrani) ${ }^{2}$

Di antara kandungan yang ada di dalam bumi (tanah) yang dapat dimanfaatkan oleh manusia adalah kandungan mineral sebagai bahan baku pembuatan besi. Alquran menegaskan tentang peranan logam besi berdasarkan firman Allah S.W.T. dalam Surat AlHadid Ayat 25 yang berbunyi:

$$
\begin{aligned}
& \text { 罗 }
\end{aligned}
$$

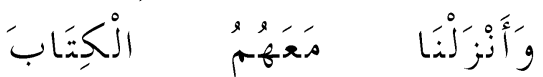

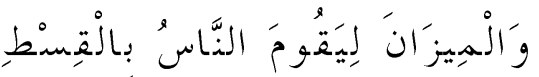

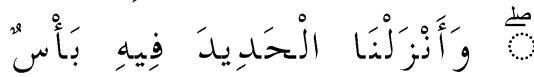

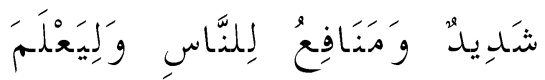

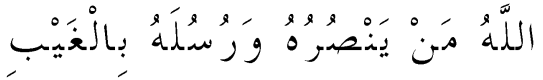

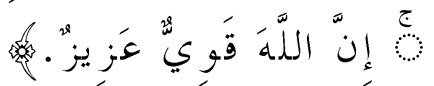

2 Afzalur Rahman. (1995). Doktrin Ekonomi Islam Jilid 1. Yogyakarta: Dana Bhakti Prima Yasa. turunkan bersama mereka AlKitab dan neraca (keadilan) supaya manusia dapat melaksanakan keadilan. Dan Kami ciptakan besi yang padanya terdapat kekuatan yang hebat dan berbagai manfaat bagi manusia, (supaya mereka mempergunakan besi itu) dan supaya Allah mengetahui siapa yang menolong agama-Nya dan rasul-rasul-Nya padahal Allah tidak dilihatnya. Sesungguhnya Allah Maha Kuat lagi Maha Perkasa."

Salah satu usaha manusia untuk mengambil keuntungan dari pasir besi adalah dengan melakukan penambangan. Salah satu lokasi yang kaya dengan kandungan pasir besi adalah wilayah Tasik Selatan tepatnya di Kecamatan Cipatujah. Dikarenakan bisnis pasir besi ini menawarkan keuntungan yang besar, maka berdatanganlah para pengusaha tambang untuk mengeksploitasi pasir besi dari wilayah tersebut.

Allah S.W.T. telah menentukan batasan-batasan dalam Al-Qur'an yang berhubungan dengan upaya manusia dalam mengekplorasi dan mengeksploitasi kekayaan alam agar upayanya tersebut tidak menimbulkan dampak negatif baik bagi lingkungan maupun pihak yang lain. Salah satu 
kegiatan eksploitasi sumber daya alam adalah penambangan pasir besi yang berlokasi di wilayah Cipatujah Kabupaten Tasikmalaya. Keberadaan kegiatan penambangan tersebut memiliki dampak positif dan negatif. Dampak positifnya diantara lain terciptanya lapangan pekerjaan bagi masyarakat yang belum memiliki pekerjaan. Dengan adanya kegiatan penambangan tersebut, respon masyarakat pun bermunculan, ada yang merespon positif dan ada pula yang negatif. Berangkat dari permasalahan tersebut, penulis berinisiatif untuk menulis sebuah karya tulis dengan judul: "Analisis Maqashid Syariah Pada Penambangan Pasir Besi Pantai Cipatujah Tasikmalaya".

\section{B. LANDASAN TEORITIS}

1. Maqashid Syariah

a. Pengertian Maqashid Syariah

Secara etimologi, maqashid syariah terdiri dari kata maqashid dan syariah. Maqashid adalah bentuk jamak dari maqshud yang berarti kesengajaan atau tujuan. Sedangkan syariah artinya jalan menuju air atau jalan menuju sumber kehidupan. ${ }^{3}$

Secara terminologi, maqashid syariah adalah kehendak Allah selaku pembuat syariah untuk memberikan kemashlahatan kepada manusia. Yaitu dengan terpenuhinya kebutuhan dharuriyah, hajiyah, dan tahsiniyah agar manusia bisa hidup dalam kebaikan dan dapat menjadi hamba Allah yang baik. ${ }^{4}$ Maqashid syariah merupakan tujuan Allah dan Rasul-Nya dalam merumuskan hukumhukum Islam. Tujuan itu dapat ditelusuri dalam ayat-ayat AlQur'an dan sunnah Rasulullah S.A.W. sebagai alasan logis bagi rumusan suatu hukum yang berorientasi kepada kemashlahatan manusia. ${ }^{5}$

Menurut Oni Syahroni, maqashid syariah adalah tujuan atau rahasia Allah S.W.T. dalam setiap hukum

3 Ika Yunia Fauzia dan Badul Kadir Riyadi. (2014). Prinsip Dasar Ekonomi Islam Perspektif Maqashid Al-Syariah. Jakarta: Kencana. hlm. 41.

4 Ika Yunia Fauzia dan Badul Kadir Riyadi. (2014). hlm 43.

5 Satria Effendi. (2009). Ushul Fiqh. Jakarta: Kencana Prenada Media Grup. hlm. 233. 
syariat-Nya. ${ }^{6}$ Sedangkan Wahbah Al-Zuhaili mengutip dari ArRaisuni, maqashid syariah adalah tujuan yang ingin dicapai oleh syariat ini untuk merealisasikan kemashlahatan hamba. $^{7}$

b. Syarat Maqashid Syariah

Menurut Wahbah Al-Zuhaili, sesuatu dapat dikatakan sebagai maqashid syariah jika memenuhi empat syarat berikut: ${ }^{8}$

1) Harus bersifat tetap, maksudnya makna-makna yang dimaksudkan itu harus bersifat pasti atau diduga kuat mendekati kepastian.

2) Harus jelas, sehingga para fuqaha tidak ada berbeda dalam penetapan makna tersebut. Contohnya memelihara keturunan (hifzhu an-nasl) yang merupakan tujuan disyariatkannya perkawinan.

3) Harus terukur, maksudnya makna itu harus mempunyai ukuran atau batasan yang

${ }^{6}$ Oni Sahroni. (2015). Maqashid Bisnis dan Keuangan Islam. Jakarta: Rajawali Pers. hlm. 2.

${ }^{7}$ Oni Sahroni. (2015). hlm. 2.

${ }^{8}$ Wahbah Al-Zuhaili. (1986). Ushul AlFiqh Al-Islami. Beirut: Darul Fikr. hlm. 541. jelas yang tidak diragukan lagi. Seperti menjaga akal (hifzhu al-aqli) yang merupakan tujuan pengharaman khamr dan ukuran yang ditetapkan adalah memabukkan.

4) Berlaku umum, artinya makna itu tidak akan berbeda karena perbedaan waktu dan tempat. Seperti syarat Islam dan kemampuan untuk memberi nafkah sebagai persyaratan kafa'ah dalam perkawinan manurut mazhab Maliki.

\section{c. Unsur Maqashid Syariah}

Ruang lingkup tujuan syariah, para ulama telah merumuskan lima tujuan diturunkannya syariah Islam yang dikenal dengan maqashid syariah. Kelima unsur tersebut adalah: ${ }^{9}$

1) Menjaga agama (hifzhudin), sebagai bentuk penjagaan Islam terhadap agama, maka Allah S.W.T. telah memerintahkan shalat, zakat,

${ }^{9}$ Abu Fahmi, Agus Siswanto, Muhammad Fahri Farid, dan Arijulmanan. (2014). HRD Syariah: Teori dan Implementasi. Jakarta: PT Gramedia Pustaka. hlm. 12. 
puasa, haji, dan lain lain.

Dengan menjalankan ibadah tersebut maka tegaklah agama seseorang.

2) Menjaga jiwa (hifzhu nafsi). Islam melindungi seluruh umat manusia dan menjaga keselamatan jiwa manusia melalui pengharaman membunuh manusia tanpa alasan yang dibenarkan oleh Islam.

3) Menjaga pikiran (hifzhu 'aql), melalui kewajiban menuntut ilmu sepanjang hayat, pelarangan minum khamr (minuman keras), narkoba, dan segala yang dapat merusak akal.

4) Menjaga keturunan (hifzhu nasl), dengan kewajiban memperbaiki kualitas keturunan, membina sikap mental generasi penerus dan diharamkan zina serta pengharaman perkawinan sedarah.

5) Menjaga harta (hifzhu almaal). Upaya syariat Islam dalam menjaga harta manusia tercermin dari pengharaman bagi Muslim memakan harta manusia dengan jalan bathil seperti mencuri, riba, menipu, korupsi, dan lain-lain.

Kelima jaminan dasar tersebut merupakan tiang penyangga kehidupan dunia agar umat manusia dapat hidup aman dan sejahtera. ${ }^{10}$ Berdasarkan tingkat kemaslahatan dan kepentingannya, kelima maqashid tersebut dibagi menjadi 3 (tiga) tingkatan, yaitu: ${ }^{11}$

1) Dharuriyat, yaitu kebutuhan yang harus dipenuhi, yang jika tidak dipenuhi akan membuat kehidupan menjadi rusak.

2) Hajiyat, yaitu kebutuhan yang seyogyanya dipenuhi, yang jika tidak dipenuhi akan mengakibatkan kesulitan

3) Tahsiniyat, yaitu kebutuhan pelengkap yang jika tidak dipenuhi akan membuat kehidupan menjadi kurang nyaman.

\section{Mashlahah}

Secara etimologi, mashlahah dapat berarti kebaikan, kebermanfaatan, kepantasan, kelayakan, keselarasan,

${ }^{10}$ Muhammad Abu Zahrah. (2017). Ushul Fiqih. Jakarta: Pustaka Firdaus. hlm. 451.

${ }^{11}$ Oni Sahroni. (2015). hlm. 5. 
kepatutan. ${ }^{12}$ Mashlahah adalah bentuk tunggal dari al-mashalih, yang searti dengan kata shalah yaitu mendatangkan kebaikan. Terkadang digunakan juga untuk istilah lain yaitu al-ishlah yang berati mencari kebaikan. ${ }^{13}$ Kata mashlahah juga disepertikan dengan almanfaat, baik artinya maupun timbangan katanya, yaitu kalimat mashdar yang sama artinya dengan kalimat ash-shalah. ${ }^{14}$ Dengan demikian mashlahah bisa diartikan sebagai sesuatu yang memiliki manfaat baik secara asal maupun melalui sebuah proses, seperti menghasilkan kenikmatan dan faedah, ataupun pencegahan dan penjagaan, seperti menjauhi kemadaratan dan penyakit. ${ }^{15}$

Secara terminologi maslahat adalah setiap perkara yang memberikan kemanfaatan dan menghapus kemadaratan. ${ }^{16}$ Menurut Al-Gazali, yang dimaksud maslahah dalam arti terminologis syar'i adalah memelihara dan mewujudkan tujuan syara' yang

12 Jamaludin Muhammad. (2003). Lisan Al-'Arab. Riyad: Darul 'Alam Al-Kutub. hlm. 348.

${ }^{13}$ H.M. Hasbi Umar. (2007). Nalar Fiqh Kontemporer. Jakarta: Gaung Persada Press. hlm. 112.

14 Rachmat Syafe'i. (2018). Ilmu Ushul Fiqh. Bandung: CV Pustaka Setia. hlm.117.

${ }^{15}$ Rachmat Syafe'i. (2018). hlm.117.

${ }^{16}$ Oni Sahroni. (2015). hlm. 3. berupa memelihara agama, jiwa, akal budi, keturunan dan harta kekayaan. Ditegaskan pula oleh Al-Gazali bahwa setiap sesuatu yang dapat menjamin dan melindungi eksistensi kelima hal tersebut dikualifikasi sebagai maslahah. Sebaliknya, setiap sesuatu yang dapat mengganggu dan merusak kelima hal tersebut dinilai sebagai mafsadah, maka mencegah dan menghilangkan sesuatu yang demikian dikualifikasi sebagai maslahah. $\quad 17 \quad$ Al-Khawarizmi memberikan definisi yang hampir sama dengan Al-Gazali, yaitu memelihara tujuan syara' (dalam menetapkan hukum) dengan cara menghindarkan kerusakan dari manusia. $^{18}$

3. Skala Prioritas Mashlahah

Dalam menentukan skala prioritas, setidaknya ada beberapa kaidah fiqh yang harus dipertimbangan. Adapun kaidah-kaidah itu di antaranya adalah:

a. Menolak kemafsadatan lebih didahulukan daripada meraih kemashlahatan. ${ }^{19}$

17 Abu Hamid Muhammad Al-Gazali. (1997). Al-Mustasfa min 'Ilm Al-Ushul, Tahqiq wa Ta'liq Muhammad Sulaiman Al-Asyqar. Juz ke-1. Beirut: Mu'assasah Al-Risalah. hlm. 416417.

18 Amir Syarifudin. (2008). Ushul Fiqh jilid 2. Jakarta: Kencana. hlm 368.

19 A. Djazuli. (2011). Kaidah-Kaidah Fikih. Jakarta: Kencana. hlm. 164. 
Kaidah ini menegaskan bahwa jika pada waktu yang sama kita dihadapkan kepada pilihan menolak kemafsadatan atau meraih kemashlahatan, maka yang harus didahulukan adalah menolak kemafsadatan.

b. Kemashlahatan yang umum lebih didahulukan daripada kemashlahatan yang khusus. ${ }^{20}$

Kaidah ini menegaskan bahwa bila berbenturan antara kemaslahatan umum dengan kemaslahatan khusus, maka kemaslahatan yang bersifat umum yang harus didahulukan, karena dalam kemaslahatan yang umum itu terkandung pula kemaslahatan yang khusus, namun tidak sebaliknya. ${ }^{21}$

\section{PEMBAHASAN}

Antusiasme masyarakat terhadap pertumbuhan praktek ekonomi syari'ah sangat tinggi, terlebih dengan menjamurnya pendirian lembaga keuangan syari'ah (LKS) baik dalam bentuk Bait At-Tamwil, BPRS, atau perbankan syari'ah. 22 Terdapat

${ }^{20}$ A. Djazuli. (2011). hlm. 166.

${ }^{21}$ A. Djazuli. (2011). hlm. 166.

${ }^{22}$ Eka Sakti Habibullah. (2017). Hukum Ekonomi Syariah dalam Tatanan Hukum perbedaan antara prinsip syari'at dan hukum Islam seperti yang dikutip Fachri Fachrudin, bahwa Jeje Zainudin menyatakan mereka tidak bersepakat dengan penggunaan kata "asas" untuk merujuk kepada "dasar, alas, dan fondamen pembentukan dan penerapan hokum Islam". Walaupun dan kamus bahasa Inggris kata "asas" memiliki makna yang sama dengan kata "principle". 23

Syari'at Islam mengandung kemaslahatan. Sehingga, umat Islam membutuhkan penerapat syari'at Islam karena seluruh kemaslahatan yang besar yang terdapat di dalamnya menuntun seseorang pada sebuah kebaikan dan kebenaran. Syari'at Islam akan selalu memiliki maslahat bagi umat manusia. Syari'at juga seperti yang diungkapkan Arijulmanan, yaitu ketentuan agama yang telah ditetapkan oleh Allah S.W.T. untuk hamba-Nya, yang berupa berbagai hukum dan ketentuan tersebut disebut sebagai syari'at karena bentuknya yang konsisten, sebagaimana yang dijelaskan dalam Surat Al-

Nasional. Al-Mashlahah: Jurnal Hukum Islam dan Pranata SosialIslam, 05(10). hlm. 693.

23 Fachri Fachrudin. (2018). PrinsipPrinsip Syari'at pada Bidang Jinayat. AlMashlahah: Jurnal Hukum Islam dan Pranata Sosial Islam, 06(02). hlm. 130. 
Ma'idah Ayat 30, bahwa Allah S.W.T. meridhai Islam sebagai agama penyempurna umat manusia. $^{24}$

Tidak diragukan lagi bahwa tujuan dari penerapan syariah Islam adalah untuk memberikan kemaslahatan bagi umat manusia. yaitu agar manusia bisa mendapatkan manfaat dan terhindar dari berbagai macam kemadaratan. Kegiatan penambangan pasir besi yang dilakukan di pantai Cipatujah Kabupaten Tasikmalaya memiliki dampak positif (manfaat) dan dampak negatif (mafsadat) bagi lingkungan.

1. Dampak Positif Penambangan Pasir Besi

a. Terbukanya Lapangan Kerja Baru Memang tidak bisa dipungkiri bahwa usaha penambangan pasir besi ini membuka peluang kerja bagi pengangguran dan warga yang berpenghasilan tidak tetap. Perusahaan yang melakukan penambangan biasanya memprioritaskan warga sekitar yang terdekat dengan lokasinya meskipun hanya sebagian saja yang berminat dan merasakan hasil dari penambangan tersebut.
b. Pemanfaatan Lahan Non Produktif

Di antara lahan yang ditambang ada lahan yang sudah tidak produktif lagi. Keberadaan usaha penambangan ini bisa menjadi peluang bagi pemilik lahan untuk memanfaatkan lahannya sehingga bisa menjadi sumber penghasilan. Selain itu juga, melalui proses reklamasi, lahan ini bisa menjadi lahan produktif dengan perjanjian antara pemilik lahan dan pengusaha tambang.

2. Dampak Negatif Penambangan Pasir Besi

a. Kerusakan Lingkungan

Pantai Cipatujah kini tidak seindah dulu. Sebelum adanya penambangan, jika anda menyusuri jalur pantai Cipatujah, Pamayang sampai Karang Tawulan, anda akan disajikan pemandangan pantai yang indah nan alami. Akan tetapi kondisi sekarang sudah berbeda, pantai-pantai indah sudah berubah
24 Arijulmanan. (2018). Revitalisasi Syariat Islam sebagai Pedoman Hidup Manusia. Al-Mashlahah: Jurnal Hukum Islam dan Pranata Sosial Islam, 06(02). hlm. 142. 
menjadi lahan galian tambang di beberapa titik. ${ }^{25}$

Selain itu juga jalan yang menghubungkan Cipatujah dan Karang Tawulan sudah mengalami kerusakan. Kerusakan tersebut diakibatkan oleh truk pengangkut pasir besi dengan tonase berat yang berlalu lalang setiap hari dengan jumlah mencapai ratusan unit.

b. Polusi Udara

Polusi udara diakibatkan oleh lalu lalang mobil truk pengangkut pasir. Diperkirakan ada sekitar 200 unit di Cikawungading dan sebanyak 350 unit truk di Ciandum yang lalu lalang dalam sehari untuk mengangkut pasir besi ke tempat penadah. $^{26}$

c. Menurunnya Penghasilan Nelayan Menurunnya penghasilan nelayan diduga karena manghilangnya beberapa biota laut. Ditulis dalam surat kabar Kabar Priangan, Ketua Rukun Nelayan Pamayang, Desa Cikawungading,

Kecamatan Cipatujah, Sana Kanci menerangkan bahwa seiring terus

${ }^{25}$ Hasil pengamatan langsung ke lokasi penambangan.

26 Hasil wawancara dengan pegawai kelurahan Ciandum, Cipatujah. berkembangnya pertambangan pasir besi di pesisir pantai Tasik Selatan, semakin dirasakan hilangnya beberapa biota laut, terutama yang hidup di wilayah perairan tepi pantai.

Bahkan Bapak Sana juga mengungkapkan, keberadaan lobster di pinggiran laut Pamayang kini menjadi hal yang langka. Sementara selama ini lobster menjadi pendulang penghasilan para nelayan, mengingat harganya yang cukup tinggi.

Hal senada pun diungkapkan Ketua RN Ciheras, Kecamatan Cipatujah, Aep, dan juga Ketua RN Cimanuk, Kecamatan Cikalong, Jajang. Aep mengungkapkan, hilangnya ikan layur pada musimnya seperti saat ini, dirasakan sejak maraknya kegiatan pertambangan pasir besi.

d. Pendangkalan Sungai

Salah satu sungai yang mengalami pendangkalan adalah sungai yang berada di Desa Ciandum. Berdasarkan keterangan dari pegawai kelurahan setempat, ketika sebelum ada kegiatan penambangan dan sungai saat itu masih dalam keadaan normal, jika ada hujan 
deras dan banjir, air sungai tumpah dan membanjiri sebagian besar perumahan warga. Bahkan sampai ketinggian 1 sampai 2 meter. Bisa dibayangkan bagaimana dalam kondisi seperti sekarang ini (setelah ada kegiatan penambangan dan sungai sudah mengalami pendangkalan) jika hujan deras dan banjir melanda perkampungan warga.

e. Meningkatnya Resiko Ancaman Gelombang Tsunami

Berbeda dengan penambangan yang dilakukan di lahan masyarakat yang jaraknya jauh dari bibir pantai, penambangan yang dilakukan tepat di bibir pantai berakibat pada meningkatnya resiko ancaman gelombang tsunami. Menurut Prof. Dr. Ir. Widyo Nugroho Sulasdi, kegiatan penambangan pasir besi dengan cara atau metode apapun, akan merusak lingkungan pesisir pantai. Fungsi pasir besi yang ada di pantai, lanjutnya, mampu meredam laju gelombang. Selain itu juga akan dapat mencegah atau menghambat abrasi pantai.
Selain itu juga penebangan pohonpohon yang ada di lahan tambang juga dapat menjadi salah satu faktor meningkatnya ancaman gelombang tsunami. Karena pepohonan yang ada di pantai berfungsi sebagai pemecah gelombang. Memang dengan reklamasi, lahan tambang akan berfungsi kembali seperti semula dengan adanya penutupan bekas galian dan penanaman kembali pepohonan, namun proses tersebut memerlukan waktu yang relatif lama, akan tetapi bahaya tsunami bisa mengancam kapan pun juga

\section{Analisis Maqashid Syariah}

Kegiatan penambangan pasir besi di Cipatujah memang memiliki manfaat, yaitu pembukaan lapangan kerja yang baru dan pemanfaatan lahan non produktif. Dengan adanya lapangan kerja baru maka pengangguran akan terkurangi, dan masyarakat mendapatkan penghasilan untuk memenuhi kebutuhan hidupnya dan bisa melangsungkan hidupnya. Hal ini memang sejalan dengan maqashid syariah, yaitu hifzhu an-nafsi (menjaga jiwa). Meskipun memang tidak semua masyarakat sekitar pantai menjadi 
pekerja pada kegiatan penambangan pasir besi tersebut. hanya sebagian masyarakat saja yang mendapatkan manfaat dengan bekerja sebagai buruh tambang.

Selain itu penambangan di lahan yang tidak produktif akan memberikan nilai ekonomis pada lahan tersebut dengan digalinya pasir besi. Hal ini akan menghindarkan dari sifat tabdzir (menyia-nyiakan harta/aset), dan sejalan dengan maqashid syariah hifzhu al-mal (menjaga harta/aset). Namun ada juga lahan produktif yang berubah fungsi menjadi tempat penambangan pasir besi.

Akan tetapi kegiatan penambangan pasir besi juga menimbulkan banyak kemadaratan/kerusakan, di antaranya adalah kerusakan lingkungan, pendangkalan sungai yang menyebabkan air membanjiri pemukiman warga jika musim hujan tiba, dan meningkatnya resiko ancaman gelombang tsunami. Dengan demikian keamanan dan keselamatan warga terancam. Hal ini sudah tentu berseberangan dengan maqashid syariah yaitu hifzhu an-nafsi (menjaga jiwa).
Selain itu kegiatan penambangan juga menyebabkan menghilangnya biota-biota laut seperti ikan layur, lobster, dan lainnnya dikarenakan habitatnya sudah rusak karena kegiatan penambangan. Inilah yang menyebabkan hasil tangkapan para nelayan menjadi berkurang. Sudah tentu hal ini mendatangkan kerugian bagi para nelayan dan berseberangan dengan maqashid syariah, dimana salah satunya adalah hifzu al-mal (menjaga harta/aset).

Berdasarkan data di atas, kegiatan penambangan pasir besi memiliki manfaat dan madarat atau mafsadat. Pada kondisi seperti ini kita dihadapkan kepada dua pilihan, yaitu menolak kemafsadatan atau meraih kemaslahatan. Maka solusi yang terbaik adalah dengan mendahulukan menolak kemafsadatan berdasarkan kaidah fiqh: "Menolak kemafsadatan didahulukan daripada meraih kemaslahatan”. 27 Oleh karena itu, dengan menolak kemafsadatan berarti kita juga meraih kemaslahatan yang menjadi tujuan penerapan hukum Islam.

Jika kita analisis lebih jauh lagi, manfaat dari kegiatan penambangan

${ }^{27}$ A. Djazuli. (2011). hlm. 164. 
pasir besi di pantai Cipatujah ini hanya dirasakan oleh beberapa orang saja. Dengan demikian kemashalatannya hanya bersifat khusus (mashlahah alkhashshah). Sedangkan dampak negatif atau madarat yang ditimbulkan oleh kegiatan penambangan tersebut bisa dirasakan oleh masyarakat yang tinggal di sekitar lokasi penambangan, baik itu yang pro maupun kontra terhadap kegiatan penambangan tersebut. Oleh karena itu, bisa dikatakan dampak negatif/ mafsadatnya lebih luas dan lebih besar dari pada manfaatnya dan. Maka penghentian penambangan pasir besi di pantai Cipatujah bisa mendatangkan kemaslahatan yang bersifat umum (mashlahah al'ammah). Bilamana kondisinya seperti demikian, dimana ada perbenturan antara kemaslahatan khusus dengan kemaslahatan umum, maka kemaslahatan yang bersifat umumlah yang harus didahulukan, berdasarkan kaidah fiqh: "Kemaslahatan yang umum lebih didahulukan daripada kemaslahatan yang khusus". ${ }^{28}$

Dengan demikian, berdasarkan dua kaidah fiqh di atas, langkah yang terbaik dalam mendatangkan kemaslahatan bagi umat yang menjadi orientasi maqashid syariah adalah dengan menghentikan penambangan pasir besi yang berada di wilayah pantai Cipatujah Kabupaten Tasikmalaya.

\section{KESIMPULAN}

Kegiatan penambangan pasir besi di wilayah pantai Cipatujah Kabupaten Tasikmalaya memang memiliki manfaat/ mashlahah, yaitu membuka lapangan kerja baru dan pemberdayaan lahan non produktif. Akan tetapi kerusakan/mafsadat yang ditimbulkan pun lebih banyak daripada manfaatnya yaitu kerusakan lingkungan, polusi udara, menurunnya penghasilan nelayan, pendangkalan sungai, dan meningkatnya resiko ancaman gelombang tsunami yang mengancam keselamatan warga pesisir pantai. Oleh karena itu, penambangan pasir besi pantai Cipatujah bertentangan dengan nilai-nilai maqashid syariah yang berorientasi kepada kemashlahatan umat.

\section{DAFTAR PUSTAKA}

\section{Sumber dari Jurnal}

Arijulmanan. (2018). Revitalisasi Syariat Islam sebagai Pedoman Hidup Manusia. Al-Mashlahah:

\footnotetext{
${ }^{28}$ A. Djazuli. (2011). hlm. 164.
} 
Jurnal Hukum Islam dan Pranata Sosial Islam, 06(02).

Fachrudin, F. (2018). Prinsip-Prinsip Syari'at Pada Bidang Jinayat. AlMashlahah: Jurnal Hukum Islam dan Pranata Sosial Islam, 06(02).

Habibullah, E.S. (2017). Hukum Ekonomi Syariah dalam Tatanan Hukum Nasional. Al-Mashlahah: Jurnal Hukum Islam dan Pranata SosialIslam, 05(10).

\section{Sumber dari Buku}

Al-Gazali, A.H.M. (1997). Al-Mustasfa min 'ilm Al-Ushul, Tahqiq wa Ta'liq Muhammad Sulaiman AlAsyqar. Juz ke 1. Beirut: Mu'assasah Al-Risalah.

Al-Zuhaili, W. (1986). Ushul Al-Fiqh Al-Islami. Beirut: Darul Fikr.

Djazuli, A. (2011). Kaidah-Kaidah Fikih. Jakarta: Kencana.

Effendi, S. (2009). Ushul Fiqh. Jakarta: Kencana Prenada Media Grup.

Fahmi, A., Siswanto, A., Farid, M.F., dan Arijulmanan. (2014). HRD Syariah: Teori dan Implementasi. Jakarta: PT Gramedia Pustaka.

Fauzia, I.Y. dan Riyadi, B.K. (2014). Prinsip Dasar Ekonomi Islam
Perspektif Maqashid Al-Syariah. Jakarta: Kencana.

Muhammad, J. (2003). Lisan Al-'Arab. Riyad: Darul Alam Al-Kutub.

Pusat Pengkajian dan Pengembangan Ekonomi Islam. (2008). Ekonomi Islam. Jakarta: PT RajaGrafindo Persada.

Rahman, A. (1995). Doktrin Ekonomi Islam Jilid 1. Yogyakarta: Dana Bhakti Prima Yasa.

Sahroni, O. (2015). Maqashid Bisnis dan Keuangan Islam. Jakarta: Rajawali Pers.

Syafe'I, R. (2018). Ilmu Ushul Fiqh. Bandung: Pustaka Setia.

Syarifudin, A. (2008). Ushul Fiqh jilid 2. Jakarta: Kencana.

Umar, H.M.H. (2007). Nalar Fiqh Kontemporer. Jakarta: Gaung Persada Press.

Zahrah, M.A. (2017). Ushul Fiqih. Jakarta: Pustaka Firdaus.

\section{Sumber Wawancara/Pengamatan}

Hasil wawancara dengan pegawai kelurahan Ciandum, Cipatujah.

Hasil pengamatan langsung ke lokasi penambangan. 